\title{
Confucian Philosophy of the Doctrine of the Mean (Zhongyong) and Compliment Responses of Chinese Workers
}

\author{
Xu Jun \\ Guangzhou Vocational College of Science and Technology, Guangzhou, China, 510550
}

Keywords: language philosophy; intercultural communication; compliment response; Doctrine of the Mean (Zhongyong); Chinese Ethics

Abstract: This empirical investigation finds the Chinese workers' compliment responses determined by their responding strategies, which are found to be influenced by the Doctrine of the Mean (Zhongyong). Zhongyong's philosophy of cautious low-profile, self-control and moderation has become Chinese people's responding strategies. The pictures of Chinese ancient coins contain Zhongyong philosophy as a Circle Outside a Square. The solution of contradictions is mainly that one side must not kill the other, but both sides should have win-win strategies, "conciliatory but not accommodating". Zhongyong would be a philosophic basis of a harmonious society.

\section{Introduction}

The compliment and response are a kind of 'adjacency pair' that must take place together (Zhao 1998, Guo 1998, Wang and $\mathrm{Xu}$ 2005). Many researchers at home and abroad are paying more attention to researches on English compliment responses. However, less attention has been paid to Chinese compliment responses. There are only a few empirical works done on the basis of actual speech materials. Even if people could find a few essays with regard to empirical works, most of them would investigate students at school and make researches by Western linguistic theories, but few would make researches on the workers in a factory or by Confucian philosophy of the Doctrine of the Mean (henceforth Zhongyong).

\section{Relevant theories}

\subsection{Confucian Philosophy of Zhongyong}

Zhongyong Philosophy is also called Confucian Philosophy or Confucian Thought (Yan 2007; The Doctrine of the Mean is the Philosophy of a Reactionary Class 1974).

Confucius said, "The true gentleman is conciliatory but not accommodating. Common people are accommodating but not conciliatory." (Confucius and Waley 1997:171).

Zhongyong's behaving philosophy is to treat everything to a turn with cautious low-profile, self-control and moderation (Ma 2009)

Zedong MAO, pre-Chairman of Chinese Communist Party, pointed out that Confucius' 
concept of Zhongyong is a great discovery and achievement, which is an important category of philosophy and worthwhile explaining. "Excess" is "left tendency" while "shortfall" is right tendency. According to our current points of view, the excess and shortfall mean that we should determine its definite quality by matching it with its quantity when a given thing is moving and developing to a certain extent at time and space which is called to find "a balance" or "moderate solution (Zhongyong)" (Yang 2002:114).

\subsection{Traditional Chinese Ethics, Moralism and Values}

Confucian Thought has become traditional Chinese ethical moral criteria, values and a important cultural base, and Chinese nation's traditional moralism (Huang 2006). According to Cui (2010), Confucianism has become the dominant ideology or thought of Chinese traditional culture.

Confucius said, "In the usages of ritual it is harmony that is prized." (Confucius and Waley 1997:9).

Confucius said, "Filial piety is the most fundamental conduct of the human being as if the moon and stars would move in heaven and all things would grow naturally on the ground." (Confucius, Mencius \& Hou 1998:7).

It is a traditional virtue for the Chinese nation to respect the aged and cherish the children, which was advocated first by Confucius in Chinese history and has been the ancient Confucian virtue or morality and then has become Chinese traditional ethics, moralism and values (Cui 2010). According to Chinese traditional ethics, moralism and values, listen

\section{Language materials and analyses}

\subsection{Language Materials}

By the Questionnaire, this empirical research has collected the actual language materials from the workers in a pharmaceutical factory in Guangzhou. The Questionnaire was designed by Ye (1995) and followed by Li \& Feng (2000) except a few necessary modifications for the context of a factory. Six colleagues had helped me collect 1221 compliment responses altogether. The validity and reliability of the whole research processes have been controlled strictly according to the plan (Xu, 2009).

As many scholars did, the collected compliment responses have been classified into three responding strategies: Acceptant Model, Harmonious Model and Refusing Model (Li \& Feng 2000, Zhou 2000 and Cen 2000).

\subsubsection{Acceptant Model and Harmonious Model}

The responding strategies of Acceptant Model are shown as follows:

(1) Compliment: Oh, you can sing very well!

(2) Response: Thank you!

The responding strategies of Harmonious Model are shown as follows:

(3) Compliment: You look smart in your new trousers!

(4) Response: One looks bright because of one's clothes!

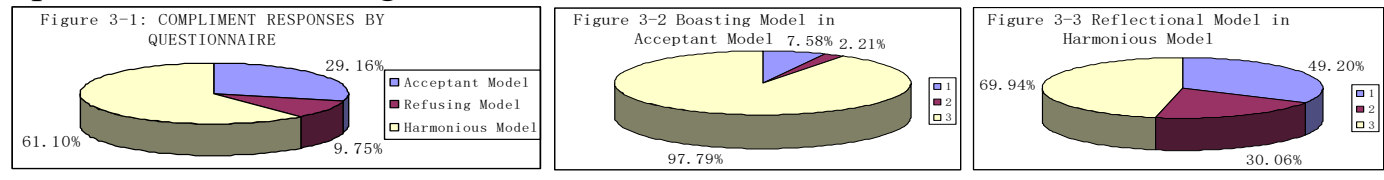




\subsubsection{Refusing Model}

The responding strategies of Refusing Model are shown as follows:

(5) Compliment: You cook very well!

(6) Response: You have praised me too much!

The statistical data by the Questionnaire are shown in Figure 3-1, 3-2 and 3-3. Harmonious Model occupies $61.10 \%$ of the total responses; Acceptant Model covers 29.16\%; and Refusing Model accounts for only $9.75 \%$. The youngest is 18 years old, and the oldest 50 . The range of the educational levels of the participants covers from junior school to university. The survey reveals that with increase in age and academic improvement, Harmonious Model has been applied more frequently, which means that Zhongyong's influences have increased.

\subsubsection{Boasting Model in Acceptant Model}

Within Acceptant Model, the responding strategies of Boasting Model could be paid more attention to and have reached only $7.58 \%$ of Acceptant Model, or $2.21 \%$ of the total responses (see Figure 3-2) as follows:

(7) Compliment: Oh, you can sing very well!

(8) Response: Certainly! I have practiced singing for many years!

\subsubsection{Reflectional Model in Harmonious Model}

The special interesting phenomena are such that the responding strategies of Reflectional Model have occupied nearly half of Harmonious Model, i.e. 49.20\% of Harmonious Model, or 30.06\% of the total responses (see Figure 3-3) as follows:

(9) Compliment: Oh, you can sing very well!

(10) Response: Thanks! You can sing very well, too!

\subsection{Zhongyong Philosophy and Responding Strategies}

The results show that the responding strategies of Acceptant Model and Harmonious Model are found to satisfy the doctrines of Zhongyong, such as Buttering one's bread on both sides; To be benevolent, lenient and friendly to everyone; Hiding one's candle under a bushel. Too much water drowned the miller. Still water runs Deep; To be cooperative, honesty and virtues are priceless; To be moderate with impartiality, going with the tide. Catching hold of any advantages; Playing to the Score. Choosing a smart roundabout way to achieve a victory. There is strength inside softness etc. According to the traditional Chinese ethical moralism, they are friendly polite responses.

The responding strategies of Refusing Model are found to satisfy the doctrines of Zhongyong, such as To be benevolent, lenient and friendly to everyone; Hiding one's candle under a bushel. Too much water drowned the miller. Still water runs Deep; To be moderate with impartiality, going with the tide. Catching hold of any advantages; Playing to the Score. Choosing a smart roundabout way to achieve a victory. There is strength inside softness etc. According to the traditional Chinese ethical moralism, they are modest responses. They are white lies. It is worth noticing that the well-intentioned Refusing Model is not really refusing the compliment, but only refuses the compliment orally and accepts it happily in heart. This is the most traditional Chinese-style modesty: too modest to accept the compliment. The listener would refuse the speaker's compliment, but the listener would not mean to offend the speaker.

It seems that the responding strategies of Boasting Model in Acceptant Model would have deviated from the doctrines of Zhongyong [see (7) and (8)].

In fact, we can find the spirit in the doctrines of Zhongyong. According to Zhongyong, one 
should behave with intelligence, such as To be moderate with impartiality, going with the tide. Catching hold of any advantages; Playing to the Score. Choosing a smart roundabout way to achieve a victory. There is strength inside softness etc. Compatibly, one's appropriate feeling of achievements could balance one's mind. So, the Boasting Model has been found to satisfy Zhongyong with the above spirit. According to the traditional Chinese ethical moralism, they are modern responses.

Furthermore, the responding strategies of Reflectional Model in Harmonious Model satisfy the doctrines of Zhongyong, such as Buttering one's bread on both sides; To be benevolent, lenient and friendly to everyone; Hiding one's candle under a bushel. Too much water drowned the miller. Still water runs Deep; To be cooperative, honesty and virtues are priceless; To be moderate with impartiality, going with the tide. Catching hold of any advantages; Playing to the Score. Choosing a smart roundabout way to achieve a victory. There is strength inside softness etc. According to the traditional Chinese ethical moralism, they are harmonious reflectional responses. .

The Boasting Model in Acceptant Model and the Reflectional Model in Harmonious Model would satisfy the direct characters of Westerners. Zhongyong has influenced people's compliment responses with Chinese-style philosophy and responding strategies. The speech acts of Chinese people have to behave well according to requirement of the Chinese moralism and ethics advocated by Zhongyong's philosophic culture.

Confucianism has become traditional Chinese ethic, moral standards and values. It is the Chinese nation's traditional virtue to respect the aged and cherish the children as civilization and politeness. Everyone must adhere to traditional moral standards, otherwise he or she would be considered unethical and bad-behaved. Chinese people living in China's ethical and cultural environments must be influenced by Chinese traditional moral values. The traditional ethics and morality and values inevitably exerts a subtle unconscious influence on Chinese speech acts. Along with Western culture impacts, enriching people's minds, everyone's speech acts have dynamic differences. It is a reminder that one nation must not lose its traditional virtues, such as ethics and morality and values when absorbing other cultures.

\section{Symmetric thinking model}

It is because of the enlightenment of Reflectional Model that we find the symmetric thinking structures. The Reflectional Model would be overt symmetric thinking structure while other models would be covert ones. All the models would contain Zhongyong's symmetric thinking structures:

(11) Compliment: Oh, you can sing very well!

(12) Response: Thanks! You can sing very well, too!

The most interesting phenomena are such that you have praised me and I should return or reflect the praise to you too. These are typical symmetric thinking structures!

A compliment (as a spear) and a response (as a shield) would be a pair of contradictions inside somebody's brain. The pictures of Chinese ancient coins contain Zhongyong philosophy as a Circle Outside a Square. It is due to the inspiration drawn by the pictures that we find a hypothesis of Zhongyong's Symmetric Thinking Model (A Theory of Balance) (see Figure 1 and Figure 2). The Model reveals that a person should have a personality of honest justice inside and treat everything outside in a smart roundabout way. This is the spirit of Confucian philosophy of Zhongyong. It is also the highest strategy urged by Wu SUN. In the Art of War, he said: 'To win in hundreds of battles is not the best strategy, but to conquest the enemy without any battles is the most perfect strategy'. 


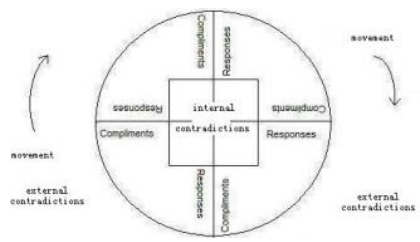

Figure 1: The Symmetric Thinking Model Hypothesis of Confucian Philosophy of the Doctrine of the Mean (Zhongyong) as a Circle Outside a Square (A Theory of Balance)

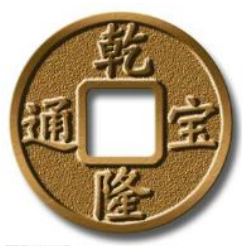

Figure 2 One Specimen of Chinese Ancient Coins

\section{Summary}

Differences between Eastern and Western philosophy are: 1) Easterners pay more attention to the personal life while Westerners lay more emphasis on the physical world; 2) Easterners pay more attention to the Right, Wrong, Goodness and Evil that Westerners regard as so-called values, but Westerners think that the so-called values are less important; 3) Easterners put morality over wisdom while Westerners put the wisdom over the morality (Zhang 2006).

Zhongyong would be the philosophic basis of a harmonious world. The "conciliatory but not accommodating" strategies are not only Zhongyong's behaving philosophy, but also the principle by which we would deal with foreign relations between countries.

\section{References}

[1] Cen, Jing. 2000. (Cultural Difference Affects Compliment Response Models). Shaoguan University Journal, No.5, Volume 21.

[2] Confucius, Mencius \& Hou, Guangfu. 1998. (Explanation of Confucian and Taoist Classics: The Analects, Filial Piety and Mencius). Dalian: Dalian Press. 1998.10.

[3] Confucius \& Waley, Arthur (Ed.). 1997. The Analects 《论语》. Beijing: Foreign Language Teaching and Research Press.

[4] Cui, Shufeng. 2010. Confucianism Influences on Chinese Traditional Culture. Papers of History Teaching Group of No.25 Middle School in Harbin City. 2010.04.07. Retrieved 2013.11.20 from baidu.com web site: http://blog.sina.com.cn/u/1726223592.

[5] Huang, Bin. 2006. (Confucianism Influences on Chinese Culture)[J], Science and Education Paper Collection, 2006.02, last half monthly: 126-127.

[6] Li, Yue-e, \& Feng, Jianghong. 2000. (Analysis of the Compliments and Responses in Mandarin Chinese), in Foreign Language and Foreign Language Teaching, No.9 2000, Total No. 137, 28-32.

[7] Ma, Yi, 2009, (There Is a Kind of Wisdom Called Zhongyong)[M], Huhehaote: Neimenggu People Press, 2009.01.

[8] Xu, Jun. 2009. On the Confucian Philosophy of the Doctrine of the Mean and Compliment Responses of Chinese Workers. Unpublished MA Thesis, Guangdong University of Foreign Studies.

[9] Yan, Shenghua. (Ed.). 2007. Confucius is Very Worried. Beijing: Science and Technology Document Press.

[10] Yang, Hong. (Ed.). 2002. [The Doctrine of the Mean (Zhongyong) and the Great Learning]. Hefei: Anhui People Press.

[11] Ye, L. 1995. Complimenting in mandarin Chinese. In Kasper, G(Ed.), Pragmatics of Chinese As Native and Target Language, 207-302. University of Hawaii, USA.

[12] Zhang, Junli. 2006. (The Revival of Confucian Philosophy). Beijing: China People University Press, 2006.09

[13] Zhou, Xiangru. 2000. (English Compliment Responses). In Journal of Wuzhou Teacher's Colledge of Guangxi, No.4, Volume 16. 